\title{
Elastic light scattering spectroscopy for the detection of pre-cancer: an overview Irving J Bigio
}

Address: Departments of Biomedical Engineering, Electrical \& Computer Engineering, Physics, Medicine, Boston University, USA

from Ist Scientific Meeting of the Head and Neck Optical Diagnostics Society London, UK. 14 March 2009

Published: 28 July 2009

Head \& Neck Oncology 2009, I (SuppI I):OI doi:I0.I I86/I758-3284-I-SI-OI

This abstract is available from: http://www.headandneckoncology.org/content/I/SI/OI

(c) 2009 Bigio; licensee BioMed Central Ltd.

Optical spectroscopy mediated by fibre-optic probes can be used to perform non-invasive, or minimally-invasive, real-time assessment of tissue pathology in-situ. The method of elastic-scattering spectroscopy (ESS) is sensitive to the sub-cellular architectural changes, such as nuclear grade and nuclear to cytoplasm ratio, mitochondrial size and density, etc., which correlate with features used by pathologists when performing histological assessment. The ESS method senses those morphology changes without actually imaging the microscopic structure. Clinical demonstrations of ESS have been conducted in a variety of organ sites, with promising results, and larger-scale clinical studies are now ongoing. We have recently developed an analytical model that extracts, from the ESS spectra, the underlying physical correlates of the tissue relating to disease. 